
Surpreendidos pela ação - mediação pelas Sociologias Pragmáticas Francesas 


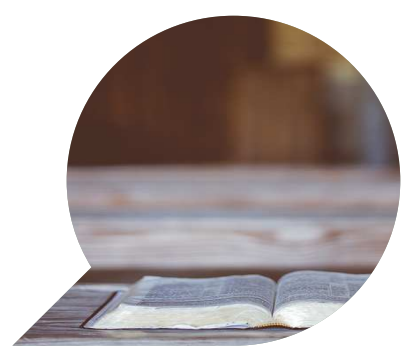

\section{Surpreendidos pela ação - mediação pelas Sociologias Pragmáticas Francesas}

Superados por la acción - mediación por las Sociologías Pragmáticas Francesas

Overtaken by action - Mediation by French Pragmatic Sociologies

TIAGO BARCELOS PEREIRA SALGADO ${ }^{1}$

Resumo: $O$ artigo apresenta como as noções de ação e de social são reformuladas pelas Sociologias Pragmáticas Francesas, composta por três vertentes: Sociologia Política e Moral, Sociologia das Associações ou Teoria Ator-Rede (TAR) e Sociologia Pragmática e Reflexiva. Ao reformularem tais noções, com base no Pragmatismo norte-americano, as Novas Sociologias, em contraste com as sociologias precedentes - humanistas, racionalistas e antropocêntricas -, incluem os não humanos na composição do social, fabricado por ações plurais e incertas. Por meio de revisão de literatura específica e também no original em francês, este trabalho esclarece a noção de mediação tal como proposta por tais abordagens sociológicas pragmáticas e esclarece essa noção na TAR. O texto conclui que a mediação é sociotécnica (híbrida), plural e incerta para a TAR. 
Palavra-chave: Ação; Mediação; Pragmatismo; Sociologias pragmáticas francesas; Teoria Ator-Rede.

Resúmen: El artículo presenta cómo las nociones de acción y de social son reformuladas por las Sociologías Pragmáticas Francesas, compuestas por tres vertientes: Sociología Política y Moral, Sociología de las Asociaciones o Teoría del Actor-Red (TAR) y Sociología Pragmática Reflexiva. Al reformular tales nociones, con base en el Pragmatismo norteamericano, las Nuevas Sociologías, en contraste con las sociologías precedentes - humanistas, racionalistas y antropocéntricas -, incluyen a los no humanos en la composición de lo social, fabricado por acciones plurales e inciertas. Por medio de revisión de literatura específica y también en el original en francés, este trabajo aclara la noción de mediación tal como se ha propuesto por estos enfoques sociológicos pragmáticos y aclara esa noción en la TAR. El texto concluye que la mediación es sociotécnica (híbrida), plural e incierta para la TAR.

Palabras-clave: Acción; Mediación; Pragmatismo; Sociologías pragmáticas francesas; Teoría del actor-red.

Abstract: The article presents how the notions of action and social are reformulated by the French Pragmatic Sociologies, composed of three branches: Political and Moral Sociology, Sociology of Associations or Actor-Network Theory (ANT) and Pragmatic Sociology. By rephrasing such notions, based on American pragmatism, New Sociologies, in contrast to previous sociologies - humanist, rationalist, and anthropocentric - include nonhumans in the composition of the social, fabricated by plural and uncertain actions. Through a review of specific literature and also in the original in French, this paper clarifies the notion of mediation as proposed by such pragmatic sociological approaches and clarifies this notion in ANT. The text concludes that mediation is sociotechnical (hybrid), plural and uncertain for ANT.

Keywords: Action; Actor-Network theory; French pragmatic sociologies; Mediation; Pragmatism. 


\section{Breve introdução}

Ao final dos anos 1970 e início dos anos 1980, em Paris, França, um conjunto de abordagens sociológicas é elaborado com a finalidade de apreender a pluralidade de ações que compõem o mundo, não mais limitadas às ações humanas. De modo distinto, a perspectiva humanista e, então, antropocêntrica, demarca as sociologias precedentes, como as formuladas por Émile Durkheim, Max Weber e Pierre Bordieu. As visadas posteriores são conhecidas como Sociologias Pragmáticas Francesas, que repensam a noção de social para incluir os não humanos nas ações sociais, considerando-os como atores. São três os ramos dessas sociologias: Sociologia das Associações ou Teoria Ator-Rede (TAR), Sociologia Política e Moral, e Sociologia Pragmática e Reflexiva (NACHI, 2006; LEMIEUX, 2018).

Com base nessas outras formulações acerca do social e da ação, propostas pelas Sociologias Pragmáticas Francesas, este artigo objetiva, de modo geral, apresentar como tais noções são elaboradas e abordadas por essas sociologias. De modo específico, este trabalho busca explicitar a noção de mediação, decorrente das reformulações de ação e social feitas pelas três abordagens, sobretudo pela TAR, que se dedica mais veementemente a essa empreitada. De modo adicional, a TAR frisa a ação não humana e procura pensá-la junto da ação humana, aspecto este já presente no pensamento pragmatista norte-americano (GRUSIN, 2015; NÖTH, 2017). Desse modo, buscamos compreender que as ações sociais são ações que enredam humanos e não humanos, tal como temos buscado desenvolver em outros trabalhos (SALGADO, 2018a, SALGADO, 2018b).

\section{Três vertentes das Sociologias Pragmáticas Francesas}

A primeira vertente das Sociologias Pragmáticas Francesas é composta por Bruno Latour, Michel Callon e John Law, entre os mais conhecidos; e por Madeleine Akrich, Anne-Marie Mol e Antoine Hennion, como pontuam Harman (2009), Blok e Jensen (2011) e Lemos (2013). A TAR é concebida no âmbito dos Estudos em Ciência, Tecnologia e 
Sociedade (CTS). O grupo de estudos de mesmo nome se organiza sob a direção de Jean-Jacques Salomon, no Conservatório Nacional de Artes e Ofícios, na França, em 1977, data de regresso de Bruno Latour da Califórnia, EUA. Nesse estado norte-americano, ele permaneceu entre 1975 e 1977, dedicando-se a um trabalho de campo no laboratório dirigido pelo neuroendocrinologista Roger Guillemin.

O propósito do grupo CTS era se diferenciar dos estudos estruturais e funcionalistas realizados pela Sociologia da Ciência, voltados para as mediações que produzem a ciência. Essa vertente investiga o conteúdo e a natureza do conhecimento científico, que resulta do endosso coletivo das crenças (BLOOR, 2009). A Sociologia das Ciências remonta ao sociólogo norte-americano Robert Merton (1910-2003), que propôs, na Escola de Columbia, um ethos para a Ciência, na qual predominava um domínio lógico-cognitivo interno ao conhecimento científico (LEMOS, 2013). Na década de 1970, o escocês David Bloor (1942-atual), da Escola de Edimburgo, fundamentado nos sociólogos Émile Durkheim, Karl Mannheim e Florian Znaniecki, propõe o Programa Forte em Sociologia das Ciências. A partir de então, Bloor supera as proposições de Merton. A proposta de Bloor é baseada nos princípios de causalidade (condições que ocasionam as crenças ou os estados de conhecimento), de imparcialidade (ambos os lados das dicotomias requerem explicação), de simetria (os mesmos tipos de causa devem ser explicados) e de reflexividade (aplicação dos padrões de explicação à própria Sociologia). Sua proposição também leva em conta as condições sociais do conhecimento científico (BLOOR, 2009).

Especificamente, a TAR compreende que a ciência é feita e deve ser estudada em ação, isto é, na prática cotidiana dos laboratórios. A ação é entendida como fazer e assim pode ser compreendida a partir do método descritivo empregado por Latour para relatar o dia a dia de engenheiros e cientistas. Essa proposta foi desenvolvida nas obras Laboratory Life: the Social Construction of Scientific Facts, escrita por Latour e pelo sociólogo britânico Steve Woolgar, em 1979, e Science in Action: How to Follow Scientists and Engineers Through Society, escrita por Latour, em 1987.

A Teoria Ator-Rede é inicialmente concebida por Michel Callon e Bruno Latour, cujo texto fundador, escrito por Callon (1986), com o título The sociology of an actor-network: the case of the electric vehicle, introduz o 
termo "ator-rede". Naquele período, outros escritos apresentavam ideias inicias da TAR, como o livro Laboratory Life, o texto Unscrewing the big Leviathan: how actors macro-structure reality and how sociologists help them to do so, escrito por Callon e Latour (1981), e o texto Pour une sociologie relativement exacte, também escrito por Callon e Latour ([1983]/2012).

A Teoria Ator-Rede se apresenta como abordagem metodológica para descrever a fabricação de fatos científicos. A descrição e a composição de relatos se baseiam na Etnometodologia proposta por Harold Garfinkel. Por essa razão, a TAR também é nomeada Sociologia das Ciências e das Técnicas, por Corcuff (2001). Ela é amplamente difundida, entre 1982 e 2006, graças ao ensino de Engenharia no âmbito do Centro de Sociologia da Inovação (CSI) da Escola de Minas de Paris.

A partir de 2007, a TAR é desdobrada no ensino de Direito, Política e Cartografia de Controvérsias no centro de pesquisa MédiaLab, afiliado à SciencesPo, o Instituto de Estudos Políticos de Paris (BLOK; JENSEN, 2011). Segundo Harman (2009), Blok e Jensen (2011) e Lemos (2013), os principais nomes que influenciam a TAR são: Gabriel Tarde, William James, John Dewey, Alfred N. Whitehead, Étienne Souriau, Algirdas Greimas, Harold Garfinkel, Michel Foucault, Gilles Deleuze, Michel Serres, Marc Augé, Philipe Descola e Isabelle Stengers.

A segunda vertente é integrada por Luc Boltanski, Laurent Thévenot e Michael Pollak, fundadores do Grupo de Sociologia Política e Moral (GSPM), da Escola de Altos Estudos em Ciências Sociais de Paris (EHESS), em 1984. Os dois primeiros foram orientandos do sociólogo francês Pierre Bordieu, durante os anos 1970, e participavam do grupo de pesquisa desse sociólogo, como destacam Corrêa (2011) e Dosse (2003). Posteriormente, o GPSM é desdobrado no Laboratório de Estudos sobre a Reflexividade (LIER), integrado por Yannick Barthe, Damien de Blic, Jean-Philippe Heurtin, Éric Lagneau, Cyril Lemieux, Dominique Linhardt, Cédric Moreaum, Cathérine Rémy e Danny Trom.

O GSPM propõe o deslocamento da crítica do agente especializado (o sociólogo) para o senso comum. Assim, ainda que também se volte para a ação, rompe com o "bourdieusismo" e passa a se interessar por "descobrir a competência reflexiva dos não-especialistas, do senso comum, [bem como] a capacidade largamente partilhada de generalização, de superação dos casos particulares" (DOSSE, 2003, 
p. 64). Outro ponto de distanciamento das ideias de Bordieu se refere à adoção de uma proposta não objetivista entre ação e estrutura noções que demarcam a definição do objeto de estudo da Sociologia. A dimensão estruturalista da proposta de Bordieu, conforme Nachi (2006), está na concepção apriorística de papéis e possibilidade de execução de ações por parte da estrutura social.

Boltanski, em entrevista a Corrêa (2016), esclarece que seu interesse pela ação e reflexividade de não especialistas é influenciado pela introdução do Interacionismo Simbólico na França. Coube a Pierre Bordieu introduzir essa vertente em tal país, sobretudo as obras de Erving Goffman, expoente da visada interacionista.

Também nomeada Sociologia da Crítica, Sociologia da Justificação ou Sociologia dos Regimes de Ação, a Sociologia Política e Moral atenta para os valores acionados pelos atores quando estes agem em momentos de incerteza e provação - dimensão axial. Essa dimensão, que atenta para os valores, soma-se às dimensões ontológica (o que a realidade e as entidades são) e epistemológica (o conhecimento sobre a realidade e as entidades). Em instantes incertos, o estado das coisas - aquilo que elas são ou como são compreendidas - é questionado e reformulado de acordo com os modos de negociação e justificação entre os atores - aqueles que se encontram em ação -, e não apenas pelo habitus deles, como concebia Bordieu.

A noção de "provação" (épreuve) se refere aos momentos em que certezas são questionadas, e aberturas para a redefinição das situações são instauradas (CHATEAURAYNAUD, 1991). Essa concepção demarca todas as Sociologias Pragmáticas Francesas, segundo Nachi (2006) e Lemieux (2007), autores que também as nomeiam Sociologias das Provações. As provações são provas de força - o sentido é próximo ao magnetismo -, com atração ou repulsão de elementos, isto é, argumentos ou proposições científicas (NACHI, 2006; MARTUCCELLI, 2015). A visada de Boltanski privilegia o eixo axiológico das ações, ou seja, observa a atribuição de valores por parte de atores às situações por eles experimentadas. Tal valor é considerado pela Sociologia Moral e Política como grandeza. Essa abordagem entende as provações também como provas de grandeza (NACHI, 2006; MARTUCCELLI, 2015).

Para as Sociologias Pragmáticas Francesas, a ação é considerada como provação, pois é marcada pela imprevisibilidade e pela incerteza, 
de modo que não sabemos de antemão o resultado das ações, quer dizer, o que elas desencadeiam e quais atores agem (NACHI, 2006). É desse modo que entenderemos a noção de "ação": como incerta e imprevisível. Isso implica dizer que o estado de coisas e os sentidos produzidos estão de acordo com quais atores agem e como eles agem, aspectos que não são definidos previamente, mas observados em ação. Esses aspectos de imprevisibilidade e de incerteza com relação à ação e aos atores é fortemente ressaltado por Latour (2005), a quem retornaremos.

A terceira vertente, por sua vez, foi fundada por Francis Chateauraynaud, ao final dos anos 1990, com a criação do Grupo de Sociologia Pragmática e Reflexiva (GSPR), também vinculado à EHESS. Isso se deu após a publicação do livro La faute professionelle : une sociologie des conflits de responsabilité, em 1991, resultante da tese de Chateauraynaud, orientada por Boltanski, e cujo um dos membros da banca foi Latour. Isso ressalta o fato de as Sociologias Pragmáticas Francesas serem contemporâneas entre si, ainda que a consolidação de uma e de outra variem alguns anos (SALGADO, 2018a).

O GSPR se dedica a compreender a formação e a transformação de argumentos em situações de discussão pública: controvérsias, crises e escândalos. Esses momentos são analisados por meio de recursos informáticos e de tecnologias de análise textual de corpora extensos (matérias em jornais, declarações, estatutos, leis, artigos científicos etc.). O software Prospéro foi desenvolvido por tal grupo para esse propósito e atenta para a categoria "provação" (épreuve), que reúne os verbos presentes nos documentos analisados. Os verbos dizem respeito às ações, aos fazeres de atores diversos, evidenciados pelos enunciados coletados e analisados (ARCE; SALGADO, 2016). O objetivo da proposta de Chateauraynaud é observar a trajetória argumentativa de variados atores ao longo do tempo, por meio de suas relações de força (influência, importância, relevância), e atentar para aquilo que futuramente será formado em decorrência de afetações entre atores. Chateauraynaud (2003, 2004, 2011, 2014, 2016) nomeia Balística Sociológica a análise do trajeto de argumentos em corpora textuais.

Tendo explicitado as principais características formativas das três vertentes das Sociologias Pragmáticas Francesas, passamos para o modo específico como elas compreendem as ações e o social. Ambas 
as noções, de ação e de social, são concebidas de maneira plural e distintas das sociologias anteriores.

\section{A pluralidade das ações e do social}

Para reformular as noções de ação e social, as três visadas mencionadas propõem uma concepção própria de ação: não individual ou restrita a um único sujeito. Disso resulta o entendimento incerto e plural da ação. Para essas sociologias, também nomeadas Novas Sociologias, por Corcuff (2001), em contraste às sociologias antecedentes, as ações são sociais porque são plurais, ou seja, enredam humanos e não humanos. Estes são tratados como plantas, animais, objetos técnicos, textos, gráficos, sentimentos, sentidos, entre outros.

As vertentes sociológicas precedentes, herdeiras da proposta filosófica humanista e racionalista de René Descartes e de Immanuel Kant a respeito da ação, apreendiam o humano como sujeito (aquele que age, ativo, conhecedor) e o não humano como objeto (aquele que sofre a ação, passivo, a ser conhecido). As Novas Sociologias visam a romper a dicotomia sujeito/objeto, considerando que objetos também podem agir - eles não apenas sofrem a ação, mas levam outros (humanos ou não) a agir (LATOUR, 2005).

De fato, esse entendimento pluralista da ação, inspirado na articulação entre ação humana e objetos do mundo, é o que caracteriza as Novas Sociologias, conforme Nachi (2006) e Lemieux (2018). Elas também reconhecem que os não humanos agem de modo independente da ação humana. Os humanos, por outro lado, se associam aos não humanos para agir. Essa ideia de que humanos se vinculam a não humanos para agir já se fazia presente no Pragmatismo norte-americano, que procurava pensar o humano junto ao não humano. A esse respeito, como destaca Grusin (2015), C. S. Peirce reconhece que humanos e não humanos agem segundo as mesmas leis de seleção natural.

William James também destaca essa relação. Em The Principles of Psychology, tal autor reconhece que os pensamentos, as emoções, os hábitos e as vontades humanas são inseparáveis de processos não humanos. James ([1909]/(2002) se utiliza do termo pragmata, de origem grega, para destacar "as coisas em sua pluralidade" e enfatizar não 
apenas a relação entre as coisas, mas que as coisas são, elas mesmas, um conjunto de relações. Não essencialista, essa pragmática dos vínculos presume, ainda, que as coisas estão sendo feitas, in process of making, como afirma James citado por Hennion (2013, p. 15), quando retoma o termo pragma (ação, em grego).

O mesmo argumento é recuperado anos depois por Hennion (2016) para ressaltar a dimensão pragmática da TAR. Esse autor destaca que o termo pragmata, que advém de pragma, equivale à agência (capacidade de ação) de actantes - termo recuperado de A. Greimas para nomear quem age em uma narrativa -, reiterando que estes são relações. Esse aspecto é central para o Pragmatismo norte-americano, pois essa perspectiva refusa, pela vertente de James, a distinção entre coisas e seus efeitos.

Latour (2005) retoma a ideia de relação para dizer que a ação e seus efeitos são indissociáveis. Para a TAR, agir é fazer agir, logo, ação e efeitos são diretamente relacionados, pois o efeito de uma ação é também uma outra ação que produz outros efeitos. Essa lógica espiralar já havia sido abordada por Dewey (1896), ainda que os autores das Sociologias Pragmáticas Francesas não o mencionem quanto à discussão e crítica que ele propõe acerca do conceito de arco reflexo na Psicologia.

Dewey (2010) também considera as coisas como relações, conforme a concepção de "experiência" - simbiose (transação) entre ser e mundo. Esta noção considera tudo o que existe como composto de relações de mútua afetação. Assim, as Novas Sociologias entendem que humanos e não humanos agem e se afetam mutuamente. O diferencial é, portanto, reconhecer a capacidade de ação de não humanos, introduzida na Sociologia pela Sociologia das Associações ou TAR a partir das concepções de Gabriel Tarde. Esta corrente considera os não humanos como as massas ausentes da Sociologia (LATOUR, 1988, 1992), isto é, como aqueles que faltavam para que a balança sociológica ficasse equilibrada, uma vez que as análises sociológicas pesavam, até então, para o lado da ação humana e privilegiavam-na em detrimento da não humana.

Cabe dizer que a herança pragmatista norte-americana das Sociologias Pragmáticas Francesas é indireta, como esclarece StavoDebauge (2012). Conforme esse autor, antes de escrever De la justification : les économies de la grandeur, em coautoria com Laurent Thévenot, 
publicada em primeira versão em 1991, obra inaugural da Sociologia Política e Moral, voltada para as justificações e para os valores acionados pelas ações de atores, Boltanski destaca que não tinha lido os autores pragmatistas norte-americanos.

A leitura de autores do Pragmatismo norte-americano se dá, por parte de Boltanski e demais membros do GSPM, apenas ao início do século XXI, conforme Stavo-Debauge (2012). Isso ocorre em função da tradução do inglês para o francês das obras originais do Pragmatismo norte-americano, naquele período. O momento de leitura e acesso às obras pragmatistas por parte dos membros do CSI e do GSPR não é mencionado por Stavo-Debauge (2012). Apesar disso, Antoine Hennion (2013), membro do CSI quando a TAR é fundada, aponta que James e Dewey são os autores pragmatistas mais lidos pelos autores afiliados à TAR, sem especificar quando se dá essa leitura.

A data precisa da aproximação de Latour com os trabalhos de James e de Dewey não é mencionada por Corrêa e Dias (2016). Apenas Stavo-Debauge (2012) menciona esse momento, ao início dos anos 2000. Os trabalhos de Francis Chateauraynaud estão mais próximos de Dewey, sobretudo pela noção de "investigação" (inquiry), que também é retomada por Latour (2012). Ao buscar menções a Peirce feitas por Latour e por outros autores da TAR, encontramos apenas o texto On selves, forms, and forces. Nesse trabalho, Latour (2014) contrasta a proposta semiótica de Peirce com a de Greimas - esta com menos ênfase na dimensão ontológica do que aquela. Por recorrer à semiótica de Greimas, Latour privilegia a ação em detrimento das distinções ontológicas entre os atores, nomeados actantes, pois considera que eles agem associados, conforme esclareceremos posteriormente.

Com relação ao GSPM e ao GSPR, Charles Sanders Peirce é mencionado nas obras: Le nouvel esprit du capitalisme, escrita por Luc Bolstanski em coautoria com Ève Chiapello em 1999; Énigmes et complots: Une enquête à propos d'enquêtes, escrita por Luc Boltanski em 2012; Experts et faussaires: pour une sociologie de la perception, escrita por Francis Chateauraynaud em coautoria com Christian Bessy em 1995; Prospéro : Une technologie littéraire pour les sciences humaines, escrita por Francis Chateauraynaud em 2003; e Argumenter dans un champ de forces : essai de balistique sociologique, escrita por Francis Chateauraynaud em 2011. Nessas obras, os autores destacam 
a concepção triádica de signo (primeiridade, secundidade e terceiridade) formulada por Peirce e enfatizam as noções de representação, sentido e interpretação.

De volta à questão dos não humanos, a inserção deles nas Ciências Sociais é igualmente destacada por Callon e Law (1997). Desde a fundação delas, a oposição entre individual e coletivo as demarca, servindo como contraste e fronteira entre a Sociologia e a Economia. $O$ acréscimo dos não humanos à balança sociológica serve, segundo tais autores, para o abandono da fonte ou origem da ação, o que redefiniu profundamente as Teorias da Ação, calcadas em Max Weber e Talcott Parsons, no período em que a TAR foi formulada.

A propósito, Latour (2005) reforça que ninguém é sujeito da ação ou, em outras palavras, que a ação não é realizada por um único sujeito; mas é plural, coletiva, distribuída entre associações humanas e não humanas. A isso, soma-se o fato de as correntes iniciais da Sociologia, sobretudo as de Émile Durkheim e de Max Weber, desconsiderarem os objetos, as tecnologias e os demais não humanos como explicação do social, ou mesmo, aquilo que deveria ser explicado para se conceber, então, uma noção de social (VRIES, 2016).

\section{A especificidade da mediação sociotécnica}

Para as Sociologias Pragmáticas Francesas, o social não é o que está dado de antemão, uma matéria ou material estático e já composto ou estruturado, mas justamente aquilo que está sendo formado à medida que os atores agem e se associam mutuamente (LATOUR, 2005). Essa ideia se fundamenta na proposta associacionista elaborada por Gabriel Tarde. Nas palavras de Tarde (2007, p. 90), "em uma sociedade, nenhum indivíduo pode agir socialmente, nem se revelar de uma maneira qualquer, sem a colaboração de um grande número de outros indivíduos, na maioria das vezes ignorado pelo primeiro". Nesse sentido, a TAR compreende que são diversos aqueles que agem, não de modo individual, mas coletivo, isto é, associativo, enredando outras ações.

As ações que desencadeiam outras ações são especificadas por Latour (2005), quando ele, de maneira didática, diferencia dois tipos de atores - intermediários e mediadores -, aos quais correspondem, 
portanto, dois tipos de ação: intermediação e mediação. A dinâmica de ação e levar à ação - ou fazer agir - é o que a TAR nomeia mediação (LATOUR, 2000b, 1994b, 2001, 2005).

A diferenciação entre intermediação e mediação é apresentada antes por Latour: "estas mediações apenas são reconhecidas então como simples intermediários, que nada mais fazem do que deslocar ou transmitir as formas puras, as únicas reconhecíveis". (LATOUR, 1994a, p. 56). Em outra passagem, da mesma publicação, Latour sublinha que

A Constituição moderna inteira já dizia que não há medida comum entre o mundo dos sujeitos e o dos objetos, mas ela anulava imediatamente esta distância ao praticar o contrário, ao medir humanos e coisas em conjunto com as mesmas medidas, ao multiplicar, sob o nome de intermediários, os mediadores. (LATOUR, 1994a, p. 59).

Nesse trecho, Latour enfatiza que a modernidade toma por intermediários o que deveria tratar como mediadores. Em outras palavras, a narrativa moderna considera os não humanos como simples projeções simbólicas que se interpõem às ações humanas, quer dizer, como aqueles que sofrem essas ações e se colocam entre elas, e não como aqueles que as realizam.

De modo amplo, foi esse "erro de categoria", para retomarmos uma das expressões empregadas por Latour (2012a) para qualificar e delimitar os diferentes modos de existência do período moderno, aquilo que contribuiu para o privilégio das ações humanas em detrimento das não humanas, não apenas em análises sociológicas, mas também em investigações filosóficas, antropológicas, psicológicas e comunicacionais, herdeiras das filosofias racionalistas de Descartes e Kant (SALGADO, 2018a).

É válido destacar que Callon não apresenta as noções de "mediador" e "mediação", apesar de ressaltar em nota que ambas as concepções são trabalhadas por Hennion (CALLON, 1990, p. 157). Com base nesse autor, Callon salienta que mediadores não apenas passam ou transmitem conteúdos, mas intervêm naquilo que transportam. Esse aspecto de alteração e mudança é retomado e explanado por Latour, para quem "faz grande diferença se os meios de produzir o social são encarados como intermediários ou mediadores" (LATOUR, 2012b, p. 64). Isso porque, se tomarmos o social como aquilo que é produzido por intermediários, 
ele mesmo é apreendido como uma macroestrutura que antecede e se sobrepõe às ações dos indivíduos humanos, posto que mobilizado por estes, em vez de ser tomado como aquilo que resulta ao final da cadeia de transformações operadas pelos diversos atores, humanos ou não.

No glossário disponível ao final do livro "A Esperança de Pandora: ensaios sobre a realidade dos estudos científicos", encontramos a seguinte definição:

O termo "mediação", em contraste com "intermediário", significa um evento ou um ator que não podem ser exatamente definidos pelo que consomem e pelo que produzem. Se um intermediário é plenamente definido por aquilo que o provoca, uma mediação sempre ultrapassa sua condição. A diferença real não é entre realistas e relativistas, sociólogos e filósofos, mas entre os que reconhecem, nas muitas tramas da prática, meros intermediários e os que admitem mediações. (LATOUR, 2001a, p. 351).

Em outra passagem, da mesma obra, Latour entende que

Um intermediário, em meu léxico, é aquilo que transporta significado ou força sem transformá-los: definir o que entra já define o que sai. Para todos os propósitos práticos, um intermediário pode ser considerado não apenas como uma caixa-preta, mas uma caixa-preta que funciona como uma unidade, embora internamente seja feita de várias partes. Os mediadores, por seu turno, não podem ser contados como apenas um, eles podem valer por um, por nenhuma, por várias ou uma infinidade. O que entra neles nunca define exatamente o que sai; sua especificidade precisa ser levada em conta todas as vezes. Os mediadores transformam, traduzem, distorcem e modificam o significado ou os elementos que supostamente veiculam. Não importa quão complicado seja um intermediário, ele deve, para todos os propósitos práticos, ser considerado como uma unidade - ou nada, pois é fácil esquecê-lo. Um mediador, apesar de sua aparência simples, pode se revelar complexo e arrastar-nos em muitas direções que modificarão os relatos contraditórios atribuídos a seu papel. (LATOUR, 2001a, p. 65).

De modo mais simples, o intermediário é aquele ator que transporta sem modificar a) a si mesmo, b) o que é transportado, e c) aquilo que possibilita o transporte (o meio). O mediador, por outro lado, é aquele ator que não apenas transporta a ação de um lugar a outro, mas a partilha, a distribui junto a outros mediadores e, ao fazer isso, transforma 
a si mesmo, o que transporta e aquilo que possibilita o transporte.

Com essa distinção didática entre dois tipos de atores, que devem ser a eles atribuídos somente em função de como agem, reconhecemos que a ação, para a TAR, é incerta, plural e alocal (não local). Tratá-la desse modo implica considerar que não sabemos de antemão quem age primeiro, como age, com quem mais age e onde age (LATOUR, 2005).

Cada uma dessas condições deve ser observada em ação, conforme as diferentes associações em curso. A ação é, assim, fonte de incerteza, e seu caráter incerto reside nos distintos atores que levam uns e outros a agir. Conforme Latour (2012b, p. 72), "a ação é encarada como um nó, uma ligadura, um conglomerado de muitos e surpreendentes conjuntos de funções que só podem ser desemaranhados aos poucos. É essa fonte de incerteza que desejamos restaurar com a bizarra expressão ator-rede".

A ação é sempre surpresa (LATOUR, 2001a), pois não sabemos ao certo quais atores serão levados à ação, bem como quais serão as entidades associadas, antes de observamos a ação. Assim, como surpresa, a ação deve permanecer, a fim de evitarmos atribuir a capacidade de ação somente aos humanos. A pluralidade da ação se encontra na sua heterogeneidade, isto é, na capacidade que humanos e não humanos possuem de agir - aquilo que a TAR nomeia de "princípio de simetria" - e na impossibilidade de reduzirmos os atores às suas ações e vice-versa - o "princípio de irredutibilidade ou irredução" (LATOUR, 2001b, p. 143).

É de maneira simétrica que a TAR busca analisar as diversas ações que fabricam o social, pois tudo o que existe pode agir, uma vez que "essência é existência e existência é ação" (LATOUR, 2001b, p. 143). Com efeito, a ação é o princípio de tudo (LATOUR, 2010), e é ela que devemos seguir se quisermos compreender a produção tanto de fatos científicos como do social (LATOUR, 2000a).

As críticas endereçadas à TAR centram-se nesse ponto relativo ao princípio de simetria. Como destaca Rocha (2015), a Teoria Ator-Rede é falível em lidar com análises ao desconsiderar as relações assimétricas e hierárquicas entre os diversos atores, por vezes assumindo que humanos e não humanos agem da mesma maneira. Outra crítica feita à TAR é relativa à questão do poder, pouco explorada por essa abordagem, tendo em vista sua discussão apenas em um texto de 1984, a saber, 
o escrito The powers of association. Nesta publicação, Latour (1984) retoma Michel Foucault para dizer que o poder deve ser tratado como consequência e não como causa da ação.

De modo mais claro, adotar a simetria como método não significa desconsiderar as assimetrias de ações humanas e ações não humanas, e nem mesmo reconhecer que humanos e não humanos agem da mesma maneira. O princípio de simetria busca não atribuir às ações humanas prevalência sobre as demais, a priori. Assim, ao considerar que os atores agem de maneira associada, a TAR evita enfatizar uma ação em detrimento de outra, tomando-a como isolada e realizada por um único sujeito. Reside nessa compreensão a ideia de mediação sociotécnica ou híbrida, isto é, feita por atores que não se reduzem a um ou outros, mas entidades que agem coletivamente, de maneira indistinta no que tange à ação.

Acerca da ação, ainda é preciso evidenciar que ela não é propriedade exclusiva da consciência humana, pois, como frisa Latour (2005), ninguém é senhor de sua ação, justamente porque são muitos os outros atores que nos levam a agir. Nesse sentido, a ação nos ultrapassa, ou melhor, somos ultrapassados por ela, ou ainda, ela é assumida por outros - a imagem é de um automóvel que é ultrapassado por outro (LATOUR, 2012b).

Como conclui Latour, "Por definição, a ação é deslocada. A ação é tomada de empréstimo, distribuída, sugerida, influenciada, dominada, traída, traduzida. Se se diz que um ator é um ator-rede, é em primeiro lugar para esclarecer que ele representa a principal fonte de incerteza quanto à origem da ação" (LATOUR, 2001a, p. 76, grifos do autor). Isso significa dizer que a ação é alocal, ou seja, distribuída em rede - a noção de rede se fundamenta na concepção de rizoma proposta por Deleuze e Guattari (2011), bem como nos princípios de acentralidade e conexão próprios a tal conceito.

Nessa ótica, a ação não é individual ou isolada, mas coletiva e realizada pelas associações de atores heterogêneos. Em ação, os atores mobilizam outros atores, os quais, por sua vez, mobilizam outros e assim sucessivamente. Reside nessa dinâmica o fazer fazer (faire faire). Não há, como argumenta Latour (2005), uma fonte ou origem da ação, pois esta se desdobra de um modo que pode ser descrito como rede. Por isso a proposta empírico-metodológica de uma teoria ator-rede, que segue e 
cartografa as mediações.

\section{Considerações finais}

A proposta de compreender as ações que compõem o mundo, tal como formulada pelas Sociologias Pragmáticas Francesas, é distinta de abordagens sociológicas francesas que as antecedem, como aquelas de Durkheim, Weber e Bordieu, em certa medida, calcadas em ideias humanistas e racionalistas de Descartes e Kant. As Novas Sociologias, portanto, ao se dedicarem a tratar a ação humana como inseparável da ação não humana, e ao considerar os não humanos como capazes de agir, tal como os humanos - o que não significa afirmar que ajam da mesma maneira -, sublinham a dimensão plural e incerta das ações. De modo mais claro, as ações são incertas porque não sabemos, de imediato, quem age, como age, com quem age e quais são os efeitos de tais ações. Elas são plurais, pois não se limitam a um único sujeito que seria senhor de sua própria ação, visto que ações são conjugadas, isto é, distribuídas entre todos os que agem. As ações produzem efeitos que também são ações que levam outros a agir.

Essa dinâmica de mútua afetação é considerada pelas Sociologias Pragmáticas Francesas como mediação, sobretudo pela Teoria Ator-Rede (TAR), uma das três vertentes dessas abordagens. A inseparabilidade das ações humanas das ações não humanas, conforme exposto, já havia sido elaborada pelo Pragmatismo norte-americano, nas formulações e publicações de Peirce, James e Dewey. A especificidade da mediação na Sociologia das Associações ou TAR reside no entendimento de que esta é sociotécnica ou híbrida, ou seja, partilhada entre os diversos atores que são levados a agir mutuamente. O modo de descrever essa distribuição de ações que enredam humanos e não humanos é a rede.

Em suma, a ação que interessa ser investigada empiricamente pela TAR é a mediação, distinta da intermediação por acarretar mudanças ou alterações naquilo que é transportado e naqueles que transportam, bem como nas condições de transporte. A mediação, como ação híbrida, permanece como surpresa. Ela nos ultrapassa, pois o que nos faz agir está, também, para além de nós.

Nesse sentido, a visada não antropocêntrica de mediação elaborada 
pelas Sociologias Pragmáticas Francesas nos impõe um desafio de pensarmos a comunicação como não restrita ao humano ou mesmo não fabricada pelos objetos técnicos apenas em sua tecnicidade. É preciso considerarmos, ainda, os enredamentos de sentidos e as dinâmicas de contato e contágio entre os atores, que podem ser humanos ou não, mas que igualmente devem ser considerados em conjunto, e não isolada e individualmente. Com efeito, a noção de social pode assumir vários sentidos, conforme as visadas que a elaboram. Especificamente para as Sociologias Pragmáticas Francesas, o social é produzido por múltiplas mediações de atores plurais, e resulta a posteriori. Reside nessa diversidade o caráter social da comunicação. Acreditamos que esse ponto pode ser melhor explorado pelas pesquisas e estudos em comunicação a partir da noção de provação.

\section{REFERÊNCIAS}

ARCE, T.; SALGADO, T. B. P. A crise da mediação jornalística em provação: uma análise textual de artigos do Medium. Parágrafo, São Paulo, v. 4, n. 2, p. 156-163, jul./dez. 2016. Disponível em: http:// revistaseletronicas.fiamfaam.br/index.php/recicofi/article/view/413.Acesso em: 15 dez. 2016.

BLOK, A.; JENSEN, T. E. Bruno Latour: hybrid thoughts in a hybrid world. London, NewYork: Routledge, 2011.

BLOOR, D. O programa forte na sociologia do conhecimento. In: BLOOR, D. Conhecimento e imaginário social. São Paulo: Unesp, 2009. Cap. 1, p. 15-44.

CALLON, M. Techno-economic networks and irreversibility. The Sociological Review, v. 38, n. S1, p. 132-161, maio 1990. Disponível em: http://onlinelibrary.wiley.com/doi/10.1111/j.1467-954X.1990. tb03351.x/abstract. Acesso em: 07 fev. 2018.

CALLON, M. The sociology of an actor-network: the case of the electric vehicle. CALLON, M.; LAW, J.; RIP, A. (Eds.). Mapping the dynamics of science and technology. London: The Macmillan Press LTD, 1986. Parte II, Cap. 2, p. 19-34.

CALLON, M.; LATOUR, B. Pour une sociologie relativement exacte. In: ROBERGE, J.; SÉNÉCHAL, Y.; VIBERT, S. (Orgs.). La Fin de la société: débats contemporains autor d'un concept classique. Québec: Athéna éditions, 1983-2012. p. 39-66. Disponível em: http://www.bruno-latour.fr/sites/default/ files/16-SOCIO-RELATIVISTE.pdf. Acesso em: 08 jun. 2017.

CALLON, M.; LATOUR. B. Unscrewing the big Leviathan: how actors macro-structure reality and how sociologists help them to do so. In: KNORR, K.; CICOUREL, A. (Eds.). Advances in Social Theory and Methodology. Londres: Routledge and Kegan Paul, 1981. p. 277-303. Disponível em: http:// www.bruno-latour.fr/sites/default/files/09-LEVIATHANGB.pdf. Acesso em: 02 maio 2017.

CALLON, M.; LAW, J. L'irruption des non-humains dans les sciences humaines : quelques leçons tirées 
de la sociologie des sciences et des techniques. In: REYNAUD, B. (Ed.). Les limites de la rationalité. Tome 2: Rationalité, éthique et cognition. Paris: La Découverte, 1997. p. 99-118.

CORCUFF, P. As Novas Sociologias: construções da realidade social. Bauru, SP: EDUSC, 2001.

CORRÊA, D. S. Entrevista com Luc Boltanski. Sociofilo, (Co)laboratório de Teoria Social, online. 2011. Publicada em 05 de julho de 2016. Disponível em: https://blogdosociofilo.wordpress.com/2016/07/05/ entrevista-com-luc-boltanski/. Acesso em: 27 nov. 2017.

CORRÊA, D. S.; DIAS, R. C. A crítica e os momentos críticos: De la Justification e a guinada pragmática na sociologia francesa. Mana, Rio de Janeiro, v. 22, n. 1, p. 67-99, abr. 2016. Disponível em: http://www.scielo.br/pdf/mana/v22n1/1678-4944-mana-22-01-00067.pdf. Acesso em: 27 out. 2017.

CHATEAURAYNAUD, F. Argumenter dans un champ de forces: essai de balistique sociologique. Paris: Éditions PETRA, 2011.

CHATEAURAYNAUD, F. La faute professionelle : une sociologie des conflits de responsabilité. Paris: Métaillé, 1991.

CHATEAURAYNAUD, F. L'épreuve du tangible : expériences de l'enquête et surgissements de la prevue. In: KARSENTI, B.; QUÉRÉ, L. (Eds.). La croyance et l'enquête: aux sources du pragmatisme. Paris: Éd. de L'EHESS, 2004. p. 167-194. Col. Raisons Pratiques, n. 15. Disponível em: https://www. gspr-ehess.com/documents/FC-Epreuve-du-tangible-2004.pdf. Acesso em: 07 ago. 2015.

CHATEAURAYNAUD, F. Pragmatique des transformations et sociologie des controverses : les logiques d'enquête face au temps long des processus. In: CHATEAURAYNAUD, F.; COHEN, Y. (Orgs). Histoires pragmatiques. Paris: Éd. de L'EHESS, 2016. p. 349-375. Col. Raisons Pratiques, n. 25.

CHATEAURAYNAUD, F. Prospéro: une technologie littéraire pour les sciences humaines. Paris: CNRS, 2003.

CHATEAURAYNAUD, F. Trajectoires argumentatives et constellations discursives: exploration socio-informatique des futurs du nanomonde. Réseaux, v. 188, n. 6, p. 121-158, 2014. Disponível em: https:// www.cairn.info/revue-reseaux-2014-6-page-121.htm. Acesso em: 07 ago. 2015.

DELEUZE, G.; GUATTARI, F. Mil platôs: capitalismo e esquizofrenia. São Paulo: Editora 34, 2011. v. 1.

DEWEY, J. Arte como experiência. São Paulo: Martins Fontes, 2010.

DEWEY, J. The Reflex Arc concept in Psychology. The Psychological Review, v. 3, n. 4, p. 357-370, jul. 1896. Disponível em: https://archive.org/details/DeweyReflexArc. Acesso em: 16 mar. 2019.

DOSSE, F. O império do sentido: a humanização das Ciências Humanas. Bauru, SP: EDUSC, 2003.

HARMAN, G. Prince of Networks: Bruno Latour and Metaphysics. Melbourne: re.Press, 2009.

HENNION, A. D'une sociologie de la médiation à une pragmatique des attachements. Sociologies. 25 de junho de 2013. Disponível em: http://sociologies.revues.org/4353. Acesso em 14 maio 2017.

HENNION, A. From ANT to Pragmatism: A Journey with Bruno Latour at the CSI. New Literary History, v. 47, n. 2, p. 289-308, 2016. Disponível em:https://muse.jhu.edu/article/631300. Acesso em: 14 maio 2017.

GRUSIN, R. (Ed.). The Nonhuman Turn. Minneapolis, MN: University of Minnesota Press, 2015. 
JAMES, W. The meaning of Truth. New York: Dover Publications Inc., 1909-2002.

LATOUR, B. A esperança de Pandora: ensaios sobre a realidade dos estudos científicos. Bauru, SP: EDUSC, 2001a.

LATOUR, B. Ciência em ação: como seguir cientistas e engenheiros sociedade afora. São Paulo: Editora UNESP, 2000a.

LATOUR, B. Enquête sur les modes d'existence: une anthropologie des Modernes. Paris: La Découverte, 2012a.

LATOUR, B. Jamais fomos modernos: ensaio de antropologia simétrica. Rio de Janeiro: Ed. 34, 1994a.

LATOUR, B. Mixing Humans with Non-Humans: Sociology of a Door-Closer. Social Problems, v. 35, p. 298-310, 1988. Disponível em: http://www.brunolatour.fr/sites/default/files/35-MIXING-H-ET-NH-GBpdf_0.pdf. Acesso em: 09 ago. 2017.

LATOUR, B. On selves, forms, and forces. HAU: Journal of Ethnographic Theory, v. 4, n. 2, p. 261-266, 2014. Disponivel em: https://www.journals.uchicago.edu/doi/pdfplus/10.14318/hau4.2.014. Acesso em: 22 mar. 2018.

LATOUR, B. On technical mediation. Common Knowledge, v. 3, n. 2, p. 29-64, 1994b. Disponível em: http://www.bruno-latour.fr/sites/default/files/54-TECHNIQUES-GB.pdf. Acesso em: 27 fev. 2015.

LATOUR, B. Reassembling the Social: An Introduction to Actor-Network-Theory. New York: Oxford University Press, 2005.

LATOUR, B. Reagregando o social: uma introdução à Teoria do Ator-Rede. Salvador, EDUFBA; Bauru, EDUSC, 2012b.

LATOUR, B. The Berlin Key or how to do words with things. In: GRAVES-BROWN, P. (Ed.). Matter, Materiality and Modern Culture. London: Routledge, 2000b. p. 10-21.

LATOUR, B. The powers of association. The Sociological Review, v. 32, supplement S1,p. 264-280, 1984. Disponivel em: <http://www.bruno-latour.fr/sites/default/files/19-POWERS-ASSOCIATIONS-GBpdf.pdf>. Acesso em: 22 maio 2017.

LATOUR, B. Where are the missing masses? The Sociology of a Few Mundane Artifacts. In: BIJKER, W.; LAW, J. (Eds.). Shaping technology/Building Society: Studies in Sociotechnical Change. Cambridge, Mass: MIT Press, 1992, p. 225-259. Disponível em: http://www.bruno-latour.fr/sites/default/ files/50-MISSING-MASSES GB.pdf. Acesso em: 17 nov. 2014.

LATOUR, B; WOOLGAR, S. La Vie en laboratoire: la production des faits scientifiques. Paris: La Découverte, 1988.

LEMIEUX, C. LEMIEUX, C. À quoi sert l'analyse des controverses ? Mil neuf cent, n. 25, p. 191-212, 1/2007. Disponível em: https://www.cairn.info/revue-mil-neuf-cent-2007-1-page-191.htm. Acesso em: 17 jan. 2017.

LEMIEUX, C. La sociologie pragmatique. Paris: La Découverte, 2018.

LEMOS, A. A comunicação das coisas: Teoria Ator-Rede e cibercultura. São Paulo: Annablume, 2013. 
MARTUCCELLI, D. Les deux voies de la notion d'épreuve en sociologie. Sociologie, v. 6, p. 43-60, 2015/1. Disponível em: https://www.cairn.info/revue-sociologie-2015-1-page-43.htm. Acesso em: 02 maio 2016.

$\mathrm{NACH}, \mathrm{M}$. Introduction à la sociologie pragmatique. Paris: Armand Colin, 2006.

NÖTH, W. Charles S. Peirce - Precursor da virada não humana. Tríade, Sorocaba, v. 5, n. 9, p. 6-17, jun. 2017. Disponível em: http://periodicos.uniso.br/ojs/index.php/triade/article/view/3026/2674. Acesso em: 15 jul. 2017.

ROCHA, I. J. Teoria ator-rede e práticas de pesquisa: notas sobre alguns usos nas pesquisas em comunicação. Verso e Reverso, São Leopoldo, v. 29, n. 71, p. 115-122, maio/ago. 2015. Disponível em: http://revistas.unisinos.br/index.php/versoereverso/article/view/ver.2015.29.71.07/4805. Acesso em: 25 jun. 2019.

SALGADO, T. B. P. A virada não humana na comunicação: contribuições da Teoria Ator-Rede e da Ontologia Orientada aos Objetos, Eco-Pós, Rio de Janeiro, v. 21, n. 2, p. 171-191, 2018a, disponível em: https://revistas.ufrj.br/index.php/eco_pos/article/view/18146/11808, acesso em 10 jun. 2019.

SALGADO, T. B. P. Fundamentos pragmáticos da teoria ator-rede para análise de ações comunicacionais em redes sociais online. 2018b. 292 f. Tese (Doutorado) - Programa de Pós-Graduação em Comunicação, Universidade Federal de Minas Gerais, Belo Horizonte, 2018.

STAVO-DEBAUGE, J. La sociologie dite "pragmatique" et la philosophie pragmatiste, une reencontre tardive. Seminário Pourquoi le Pragmatisme?, Villa Vigoni, Itália, 15 a 18 de junho de 2012. Disponível em: http://www.academia.edu/2644253/_La_sociologie_dite_pragmatique_et_la_philosophie_pragmatiste_une_rencontre_tardive_. Acesso em: 05 abr. 2017.

TARDE, G. Monadologia e sociologia - e outros ensaios. São Paulo: Cosac Naify, 2007.

VANDENBERGHE, F. Teoria social realista: um diálogo franco-britânico. Belo Horizonte: Ed. da UFMG; Rio de Janeiro: luperj, 2010.

VRIES, G. Bruno Latour. Cambridge, UK; Malden, MA: Polity Press, 2016. [Key Contemporary Thinkers] 


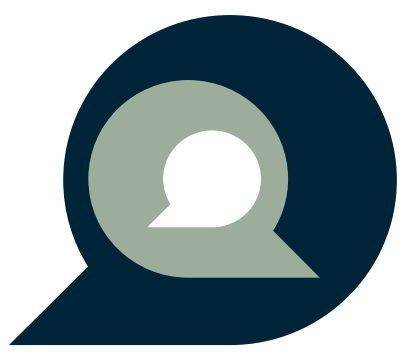

